\title{
Substituição valvar por valva aórtica homóloga montada em suporte e preservada pelo glutaraldeído: estudo multicêntrico
}

Ênio BUFFOLO*; Cláudio A. SALLES**; José VANDERLEY NETO ${ }^{\star \star \star *}$; José Telles de MENDONÇA****; Ivan S. Joviano CASAGRANDE ${ }^{\star \star \star *}$; José Carlos S. ANDRADE*; Honório PALMA*

BUFFOLO, E.; SALLES, C. A.; VANDERLEY NETO, J.; MENDONÇA, J. T.; CASAGRANDE, I. S. J.; ANDRADE, J. C. S.; PALMA, H. - Substituição valvar por valva homóloga montada em suporte e preservada pelo glutaraldeído: estudo multicêntrico. Rev. Bras. Cir. Cardiovasc., 3(1): 1-8, 1988.

RESUMO: A substituição valvar por valva aórtica homóloga montada em suporte flexível e preservada pelo glutaraldeído é procedimento original e informaçōes preliminares já foram relatadas anteriormente. O objetivo do atual estudo multicêntrico é apresentar os resultados tardios em grupo maior de pacientes, nos quais uma ou mais valvas cardiacas foram substituídas por valva aórtica homóloga. Os autores analisam os resultados em 118 pacientes selecionados, considerados de alto risco para implante de próteses biológicas, em virtude de apresentarem idades inferiores a 15 anos, ou, ainda, por calcificação de próteses biológicas implantadas anteriormente. As idades variaram de 5 a 66 anos (mediana 20 anos), sendo que $62(52,5 \%)$ tinham idade igual ou inferior a 15 anos e $18(15,3 \%)$ pacientes eram portadores de próteses biológicas calcificadas. Neste grupo de 118 pacientes, em 88 foi realizada a substituiçăo da valva mitral isolada; em 9, substituição mitral e aórtica; em 8 , substituição aórtica isolada e, em 2, substituição tricúspide. A mortalidade hospitalar foi de 2,5\% (3/118), sendo que o seguimento pós-operatório compreendeu 2614 meses/pacientes, sendo possível obter informações atualizadas em $91 \%$ dos sobreviventes. A curva atuarial de sobrevida, ao final de 36 meses, foi de $94,9 \%$, tendo ocorrido apenas 3 óbitos tardios, nos 115 pacientes que receberam alta hospitalar. Estes resultados são superiores aos esperados para as outras próteses biológicas, em nossa experiência e na da literatura, e permitindo a recomendação de seu uso, parecendo constituir-se em um avanço, especialmente na substituição valvar de pacientes jovens.

DESCRITORES: valvas cardiacas, homólogas, cirurgia; valvas cardíacas, cirurgia.

\section{INTRODUÇÃO}

Os substitutos valvares que utilizam tecidos biológicos têm merecido a preferência dos cirurgiōes cardio- vasculares, em situaçōes nas quais o uso de medicação anticoagulante é inviável, por contra-indicação do uso do mesmo, ou, ainda, pelas dificuldades do manejo da droga em populações menos favorecidas. Essas próte\footnotetext{
Belo Horizonte, MG, Brasil.

Apresentado ao 15: Congresso Nacional de Cirurgia Cardiaca. Rio de Janeiro, RJ, 8 e 9 de abril, 1988.

Laureado com o "Prêmio de Cirurgia Cardíaca - 1988"

- Da Escola Paulista de Medicina.

*. Do Hospital das Clinicas da Universidade Federal de Minas Gerais.

... Da Santa Casa de Maceió.

*... Do Hospital de Cirurgia de Aracajú.

..... Do Laboratório Labcor.

Endereço para separatas: Ênio Buffolo. Rua Borges Lagoa, 783, 5\% andar. 04038 São Paulo, SP. Brasil.
}

Trabalho realizado na Disciplina de Cirurgia de Tórax da Escola Paulista de Medicina. São Paulo. SP; no Hospital das Clínicas da Universidade Federal de Minas Gerais, Belo Horizonte, MG; na Santa Casa de Maceió, AL; no Hospital de Cirurgia de Aracajú, SE e no Laboratório Labcor. 
BUfFOlO, E.; SALLES, C. A.; VANDERLEY NETO, J.; MENDONÇA, J. T.; CASAGRANDE, I. S. J.; ANDRADE, J. C. S.; PALMA, H. - Substituição valvar por valva aórtica homóloga montada em suporte de glutaraldeído: estudo multicêntrico. Rev. Bras. Cir. Cardiovasc., 3(1): 1-8, 1988.

ses biológicas têm o atrativo de propiciar uma excelente qualidade de vida, aliada ao satisfatório desempenho hemodinâmico e à dispensa do uso do anticoagulante.

Apresentam, todavia, os inconvenientes da biodegradação tardia e a conseqüente necessidade de reintervenção, sendo que, em grupos etários mais jovens, a expectativa de uma durabilidade superior a 5 anos é pequiena $^{5,6,7,11,16,19}$.

A procura da literatura de um substituto valvar biológico mais duradouro é antiga. Assim, diversos tecidos autógenos, ou homólogos, já foram testados no passado, como pericárdio ${ }^{20}$, diafragma', fáscia lata e mesentério autógenos ${ }^{2}{ }^{17}$, dura-máter homóloga ${ }^{14}, \mathrm{ou}$, ainda, tecidos autógenos de reação ao silicone ${ }^{12}$, com resultados imediatos satisfatórios, mas deteriorando, progressivamente, com o decorrer dos anos.

Os resultados das substituições valvares por tecidos biológicos só melhoraram com o emprego de próteses heterólogas de porco, ou o pericárdio bovino, tratadas pelo glutaraldeído e que passaram a ser os representantes mais expressivos deste grupo de próteses artificiais.

Todavia, de todos os tecidos biológicos empregados, os que foram mais testados e ofereceram resultados mais consistentes, a longo prazo, foram as valvas aórticas homólogas conservadas ou frescas ${ }^{3,4,15}$.

Anteriormente, haviamos utilizado valvas aórticas homólogas preservadas em álcool etílico e montadas em suporte e, apesar da elevada incidência de disfunçōes, após os 5 anos, nos surpreenderam alguns resultados tardios com 16 anos de evolução, apesar da precária e artesanal montagem das mesmas ${ }^{8}$.

Entusiasmados com estes resultados e constatando, na literatura, experiências clínicas favoráveis, a longo prazo, com valvas aórticas homólogas frescas ou criopreservadas $^{13}$, nos interessou oferecer a tecnologia moderna de preservação de tecidos através do glutaraldeído às valvas aórticas homólogas, o que constitui experiência original, dentro da literatura compulsada.

O objetivo do presente trabalho é apresentar resultados em maior tempo de seguimento e em grupo maior de pacientes, atualizando experiência anterior do mesmo estudo multicêntrico ${ }^{18}$.

\section{CASUÍSTICA E MÉTODO}

$\mathrm{Na}$ elaboração do protocolo do presente trabalho, foram selecionados Serviços que pudessem concentrar, em curto período de tempo, casuística na qual participassem, prioritariamente, pacientes de grupos etários jovens.
Sendo assim, a indicação principal para a utilização da valva aórtica homóloga montada em suporte seria a de crianças abaixo da idade de 15 anos, ou, ainda, pacientes com disfunções de próteses biológicas previamente implantadas, a fim de que se pudesse testar, convenientemente, o substituto valvar proposto.

Do início da investigação clínica, em outubro de 1984 até fevereiro de 1988 , foram operados 118 pacientes, sendo 60 do sexo feminino $(50,8 \%)$ e $58(49,2 \%)$ do sexo masculino, com idades variáveis de 5 a 66 anos, oscilando em torno da mediana 20 anos.

Dos 118 pacientes operados, $62(52,5 \%)$ tinham idade igual ou inferior a 15 anos, e $18(15,3 \%)$ eram portadores de próteses heterólogas com disfunção, previamente implantadas.

Quanto à posição, em 110 (85,3\%), ela foi implantada em posição mitral e, em 17 , em posição aórtica,

TABELA 1

DISTRIBUICYÃO DAS DIVERSAS PATOLOGIAS OPERADAS

$$
\text { VALVA HOMOLLOGA - ESTUDO MULTICENNTRICO }
$$

\section{PATOLOGIAS}

\begin{tabular}{lr}
\hline - Insuficiência Mitral & -43 \\
- D. D. Mitral & -10 \\
- Estenose Mitral & -10 \\
- Mitro-Aórtica & -18 \\
- D. D. Aórtica & -4 \\
- Insuficiência Aórtica & -2 \\
- Mitro Tricuspídeo & -8 \\
- Mitro-Aórtico-Tricuspídeo & -2 \\
- Ins. Mitral + Ins. Aórtica + SubAo + PCA & -1 \\
- Est. Aórtica Congênita & -1 \\
- Transposição Corrigida & -1 \\
- Reoperaçōes & -18 \\
& \\
&
\end{tabular}

TABELA 2

DISTRIBUICATO DOS PROCEDIMENTOS REALIZADOS NOS 118 PACIENTES DO PRESENTE ESTUDO

VALVA HOMÓLOGA - ESTUDO MULTICEANTRICO

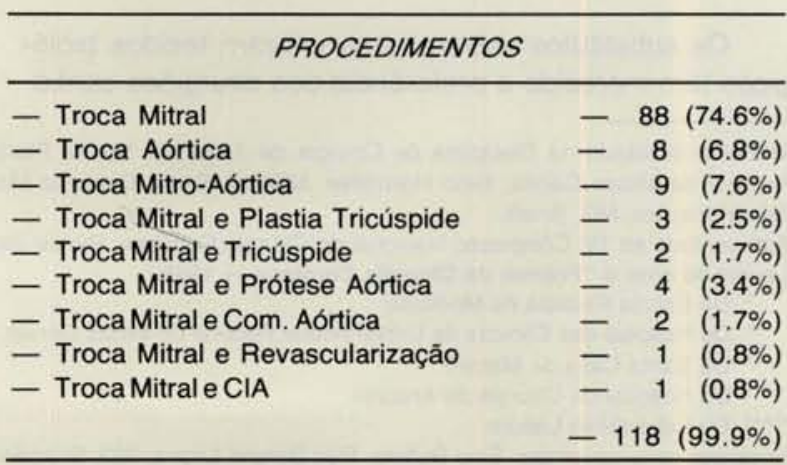


BUFFOLO, E.; SALLES, C. A.; VANDERLEY NETO, J.; MENDONÇA, J. T.; CASAGRANDE, I. S. J.; ANDRADE, J. C. S.; PALMA, H. - Substituição valvar por valva aórtica homóloga montada em suporte de glutaraldeido: estudo multicêntrico. Rev. Bras. Cir. Cardiovasc., 3(1): 1-8, 1988.

sendo que 9 pacientes têm 2 próteses, uma em posição mitral e outra em posição aórtica. As lesōes e os procedimentos realizados acham-se representados nas Tabelas 1 e 2 .

Os pacientes foram acompanhados com informações atualizadas em $91 \%$ deles, por período de 2614 meses/pacientes, sendo que metade apresenta seguimento superior a 22 meses.

Quanto ao tipo funcional pré-operatório, predominou a classe funcional III da NYHA $-61 / 118(51,7 \%)$, sendo que $46(39 \%)$ estavam na classe IV e $11(9,3 \%)$, na II.

As valvas aórticas homólogas eram obtidas no Instituto Médico Legal, de cadáveres de pessoas falecidas há menos de 12 horas e com idades inferiores a 40 anos. As valvas assim obtidas foram tratadas pelo processo do glutaraldeído à semelhança do tratamento dos tecidos heterólogos e após verificação da integridade dos tecidos, através do estudo histológico, eram montadas em suporte flexível de Celcon revestido por Dacron e fornecidas pelo laboratório Labcor, para as equipes constantes do presente estudo multicêntrico (Figura 1).

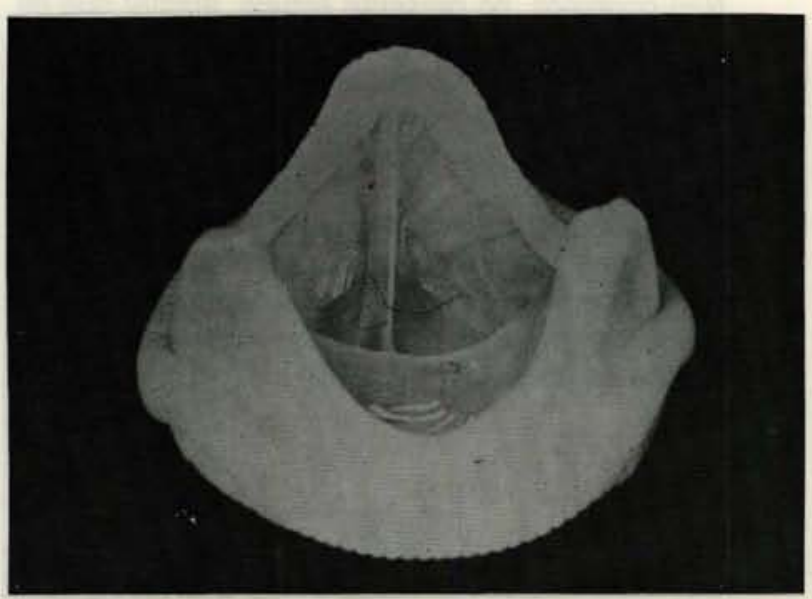

Fig. 1 - Fotografia da valva aórtica homóloga conservada em glutaraldeido e montada em suporte semi-flexivel Labcor.

\section{RESULTADOS}

Dos 118 pacientes operados, $3(2,5 \%)$ faleceram nos primeiros 30 dias, sendo as causas de morte: mau débito cardiaco (1), infecção pulmonar com endocardite infecciosa (1) e lesão neurológica em decorrência de parada cardíaca (1), sendo que, destes 3 óbitos, apenas 1 pode ter relação com a prótese implantada.

Desta forma, 115 pacientes receberam alta hospitalar e ficaram em acompanhamento ambulatorial. No período médio de seguimento de 22 meses, ocorreram
3 outros óbitos, primariamente decorrentes de endocardite fúngica ao redor do 3 ? mês (1), insuficiência cardiaca refratária no 5 : mês (1) e edema agudo dos pulmões em uma criança aos 14 meses de evolução, com função ventricular razoavelmente conservada, na qual poderíamos levantar a hipótese de calcificação da prótese, o que não foi possível confirmar em 'virtude do óbito ter ocorrido em cidade do interior do Estado de São Paulo e de maneira mais ou menos súbita.

Desta forma, $94,9 \%$ dos pacientes encontram-se vivos, ao final do período de observação do estudo (Gráfico 1).

\section{GRÁFICO 1}

CURVA DE EXPECTATIVA DE VIDA PARA OS PACIENTES PORTADORES DE PRÓTESES HOMÓLOGAS. A CURVA INFERIOR É A DA EXPECTATIVA DE VIDA EM CRIANCAS SUBMETIDAS A SUBSTITUIÇÃO VALVAR EM ESTUDO ANTERIOR"

VALW HOMOLOGA - ESTUDO MULTICENTRICO EXPECTATIVA DE VIDA

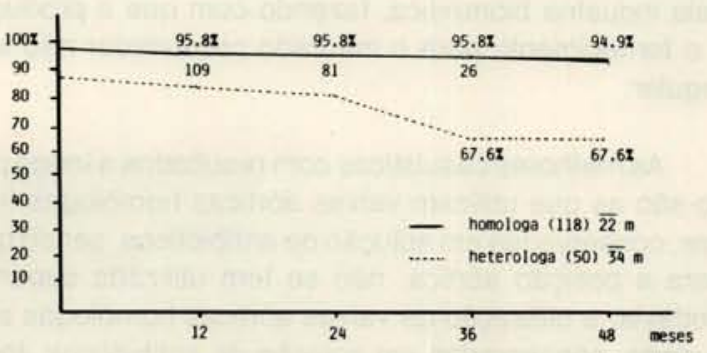

A evolução do tipo funcional foi favorável, tendo ocorrido melhoria de um ou mais tipos, para a maioria dos pacientes. Assim, no pré-operatório, $71 \%$ dos pacientes estavam em classe funcional III ou IV, sendo que a avaliação clínica pós-operatória mais recente encontrou $91,2 \%$ (103 pacientes) dos casos em classe funcional I (Figura 2).

VALVA HOMOLOGA - ESTUDO MULTICERTRICO CLASSE FUMCIOMAL PRE E POS
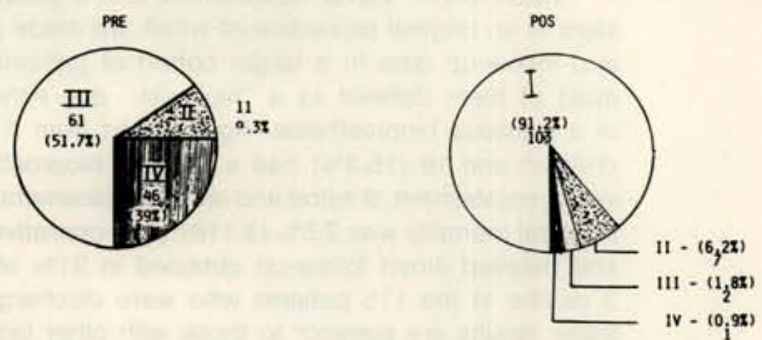

Fig. 2 - Evoluçao da classe funcional após a substituiçăo valvar.

Quanto às complicaçōes tardias de disfunção da prótese, elas ocorreram em 3 pacientes $(2,6 \%)$, exigindo 
BUFFOLO, E.; SALLES, C. A.; VANDERLEY NETO, J.; MENDONÇA, J. T.; CASAGRANDE, I. S. J.; ANDRADE, J. C. S.; PALMA, H. - Substituição valvar por valva aórtica homóloga montada em suporte de glutaraldeído: estudo multicêntrico. Rev. Bras. Cir. Cardiovasc., 3(1): 1-8, 1988.

reoperação, aos 13 meses em 2 deles, e aos 12 meses no remanescente, em crianças com 10, 12 e 16 anos de idade.

Um estudo mais detalhado a respeito de disfunções leves (espessamento do tecido, ou calcificações incipientes), através da ecodopplercardiografia, encontra-se em andamento e será objeto de publicação futura.

\section{DISCUSSÃO}

A substituição de valvas cardiacas por valvas aórticas homólogas, curiosamente não tem sido utilizada em larga escala, na maioria dos Serviços de cirurgia cardíaca, apesar dos indiscutiveis melhores resultados a longo prazo.

Entre os fatores em jogo, devemos considerar a dificuldade na obtenção das valvas nos institutos médicolegais e os óbices da comercializaçāo destas próteses pela indústria biomédica, fazendo com que a produção e o fornecimento para o mercado consumidor não seja regular.

As melhores casuísticas com resultados a longo prazo são as que utilizam valvas aórticas homólogas frescas, conservadas em soluçāo de antibióticos, sendo que, para a posição aórtica, não se tem utilizado suporte ${ }^{4}$. Todavia, a utilização de valvas aórticas homólogas sem suporte, conservadas em solução de antibióticos, torna a substituição valvar artesanal e restrita a pequeno e privilegiado grupo de pacientes, limitando sua aplicação exclusivamente à posição aórtica.
Com a finalidade de facilitar o emprego mais rotineiro deste tipo de substituto valvar, resolvemos aplicar às valvas homólogas a tecnologia já bem conhecida da conservação de tecidos pelo processo do glutaraldeído, aplicado anteriormente com sucesso, aos tecidos heterólogos. Curiosamente, não encontramos referência, na literatura, de estudos semelhanteś.

O presente trabalho analisa, então, originalmente, os primeiros resultados obtidos com esta técnica, sendo que, na elaboração de seu protocolo, sugerimos o uso prioritário da valva homóloga em pacientes de alto risco, para a biodegradação de tecidos biológicos, quais sejam, grupos etários jovens e pacientes com próteses biológicas calcificadas. Em nosso material, estas condiçōes foram observadas em 80 , dos 118 pacientes $(67,8 \%)$.

Os resultados, ao final do periodo de observação (22 meses, em média), revelam uma curva atuarial de sobrevida de $94,9 \%$, o que é extraordinariamente favorável, se compararmos a estudos anteriores com tecidos heterólogos ${ }^{11}$. Devemos, entretanto, ressaltar que a mortalidade hospitalar muito baixa de $2,5 \%$ contribuiu muito para esta expectativa de vida, o que não aconteceu em nossa experiência anterior.

Não podemos, no presente estudo, afirmar que os 112 pacientes em observação tenham suas próteses isentas da biodegradação inicial, uma vez que apenas um grupo de 40 pacientes encontra-se sob a vigilância da ecodopplercardiografia seriada.

Os resultados, apesar do tempo de observação relativamente curto, sugerem que as valvas aórticas homólogas constituem opçāo válida e promissora para a substituição de valvas cardiacas, especialmente nas condiçōes especiais de grupos etários jovens.

BUFFOLO, E.; SALLES, C. A.; VANDERLEY NETO, J.; MENDONÇA, J. T.; CASAGRANDE, I. S. J.; ANDRADE, J. C. S.; PALMA, H. - Valvar replacement with a glutaraldehyde preserved stent-mounted homologous aortic valve: a multicenter study. Rev. Bras. Cir. Cardiovasc., 3(1): 1-8, 1988.

ABSTRACT: Valvar replacement with a glutaraldehyde-preserved, homologous aortic valve in a flexible stent is an original procedure of which we made preliminary reports. We now present up-dated information and follow-up data in a larger cohort of patients. Until now 118 patients have received the prosthesis, most of them defined as a "high-risk" due either to age less than 15 years old or due to calcification of a previous bioprosthesis. Ages varied from 5 to 66 years (median: 20 y/o); 62 patients (52.5\%) were children and $18(15.3 \%)$ had a calcified bioprosthesis. The procedures performed were 88 isolated mitral valve replacement, 9 mitral and aortic replacement, 8 isolated aortic valve and 2 isolated tricuspid substitution. Hospital mortality was $2.5 \%$ (3/118); post-operative follow-up consisted of 2614 months/patient with complete and detailed direct follow-up obtained in $91 \%$ of survivors. Survival was $94.9 \%$, at 36 months with only 3 deaths in the 115 patients who were discharged from hospital. In our experience and in the literature these results are superior to those with other biological prosthesis; it seems likely that this prosthesis will be highly recommended, specially for children, if these results are maintained in longer periods.

DESCRIPTORS: heart valves, homologous, surgery; heart valves, surgery. 
BUFFOLO, E.; SALLES, C. A.; VANDERLEY NETO, J.; MENDONÇA, J. T.; CASAGRANDE, I. S. J.; ANDRADE, J. C. S.; PALMA H. - Substituição valvar por valva aórtica homóloga montada em suporte de glutaraldeido: estudo multicêntrico. Rev. Bras. Cir. Cardiovasc., 3(1): 1-8, 1988.

\section{REFERÊNCIAS BIBLIOGRÁFICAS}

1 ABSOLON, K. B.; HUNTER, S. W.; QUITLEBAUM, F. W. - A new technique for cardiac valve construction from autologous diaphragm. Surgery, 46(6): 1078-1083, 1959.

2 ARCHER, G. G. - A method of moulding autogenous tissue with a view to the manufacture of living cardiac valve prosthesis. Br. J. Surg., 52(7): 973-976, 1965.

3 BARRAT-BOYES, B. G. - Long-term follow-up of aortic valvar grafts. Br. Heart J., 33(Supl.): 60-64, 1971.

4 BARRAT-BOYES, B. G. - Long-term follow-up of patients receiving a free-hand antibiotic sterilized homograft aortic valve. In: RABAGO, F. \& COOLEY, D. eds. Heart valve replacement. New York, Futura Publishing Co., 1987. p. 167.

5 BEN-ISMAIL, M.; KAFSI, N.; TAKTAK, M. - Prothèse valvulaire chez l'enfant: a propos de 95 cas. Arch. Mal. Coeur, 72(7): 739-746, 1979.

6 BERRY, B. E.; RITTER, D. G.; WALLACE, R. B.; McGOON, D. C.; DANIELSON, G. K. - Cardiac valve replacement in children. J. Thorac. Cardiovasc., Surg., 68(4): 705-710, 1974.

7 BROFMANN, P. R. - Estudo da evoluçāo de pacientes jovens portadores de bioprótese de dura-máter em posição mitral. São Paulo, SP, 1980. (Tese Mestrado — Faculdade de Medicina da USP.).

BUFFOLO, E. - Substituição da valva aórtica ou mitral por valva aórtica homóloga montada em suporte. São Paulo, SP, 1973. (Tese Doutorado - Escola Paulista de Medicina).

9 GEHA, A. S.; LACKS, H.; STANSEL, H. C.; CORNHILL, J. F.; KILMAN, J. W.; BUCKLEY, M. J.; ROBERTS, W. C. - Late failure of porcine valve heterografts in children. J. Thorac. Cardiovasc. Surg., 78(3): 351-364, 1979.

10 GIMENEZ, A. C.; BUFFOLO, E.; FORTE, V.; ANDRADE, J. C. S.; GODOY, M. F.; SUCCI, J. E.; GALLUCCI, C. - Resultados tardios de pacientes portadores de valva homóloga montada em suporte na substituição de valvas cardíacas. Rev. Bras. Med., 33(1): 48-53, 1976.

11 GODOY, M. R.; BRANCO, J. N. R.; SOARES, H. C.; LEÃO, L. E. V.; CARVALHO, A. C. C.; GIMENES, A. C.; RIBEIRO, E. E.; SUCCI, J. E.; ANDRADE, J. C. S.; ALBERTINI, M. V.; VENTRIGLIA, C. R.; GALLUCCI, C. Resultados a longo prazo da substituiçāo valvar em crianças. Arq. Bras. Cardiol., 37(4): 325-329, 1981.

12 LOUGHRIDGE, B. P.; ROBERTS, L. B.; SEETAPUN, A:; SHADID, E. A.; WILLIAMS, R. G. - Use of structured fibrocollagenous tissue in cardiac valves. Surg. Forum, 16(1): 168-170, 1965.
13 O'BRIEN, M. F.; STAFFORD, E. G.; GARDNER, M. A. H.; POHLNER, P. G.; McGIFFIN, D. C. - A comparison of aortic valve replacement with viable cryopreserved and fresh allograft valves, with a note on chromosomal studies. J. Thorac. Cardiovasc. Surg., 94(6): 812-823, 1987.

14 PUIG, L. B. \& VERGINELLI, G. - Válvulas cardiacas de dura-máter homóloga. Rev. Paul. Med., 78(1): 33 , 1971. (Nota prévia).

15 ROSS, D. N.; YATES, A. K.; WRIGHT, J. E. C. - Replacement of aortic valve with unsupported fascia lata: report on technique and results in 43 cases. Br. Heart J., 33: 611, 1971. (Resumo)

16 SADE, R. M.; BALLENGER, J. F.; HOHN, A. R.; ARRANTS, J. E.; RIOPEL, D. A.; TAYLOR, A. B. - Cardiac valve replacement in children: comparison of tissue with mechanical prosteses. J. Thorac. Cardiovasc. Surg., 78(1): 123-127, 1979

17 SENNING, A. - Aortic valve replacement with fascia-lata. Acta Chir. Scand., 356(1): 17-20, 1966.

18 SUCCI, J. E.; BUFFOLO, E.; SALLES, C. A.; CASAGRANDE, I. S. J.; VANDERLEY NETO, J.; MENDONÇA, J. T.; VESTRI FILHO, R.; JARAMILLO, I. A. - Substituição valvar por válvula aórtica homóloga conservada em glutaraldeído: estudo multicêntrico. Rev. Bras. Cir. Cardiovasc., 1(2): 20-23, 1986.

19 TEIXEIRA NETO, J. A.; STOLF, N. A. G.; PUIG, L. B.; SOSA, E.; PILEGGI, F.; BITTENCOURT, D.; VERGINELLI, G.; ZERBINI, E. J. - Substituição de valvas cardiacas por próteses em crianças e pacientes jovens. Arq. Bras. Cardiol., 28(4): 409-415, 1975.

20 TEMPLETON, J. \& GIBBON Jr., J. H. - Experimental reconstruction of cardiac valves by venous and pericardial grafts. Ann. Surg., 129(2): 161-176, 1949.

\section{Discussão}

\section{PROF. HUGO FELIPOZZI \\ São Paulo, SP}

Desejamos agradecer à Comissão Organizadora, por me haver incluido como comentarista de um trabalho da excelência que todos nós terminamos de testemunhar e, principalmente, porque nós conhecemios, desde o conceito inicial do Dr. Ênio Buffolo, e isto há mais de 15 anos. Naquela época, o processo de conservação, ou de tratamento utilizado foi o do álcool. Desde aquela época, o Dr. Ênio, nós sabemos, mantém essa idéia e, agora, vemos a excelência dessa montagem feita. E agora com um tratamento por um método bioquímico que, realmente, oferece maiores vantagens, pelas experiências já tidas nos enxertos heterólogos, de modo que, em toda a sua concepção, é de se esperar, realmente, 
BUFFOLO, E.; SALLES, C. A.; VANDERLEY NETO, J.; MENDONÇA, J. T.; CASAGRANDE, I. S. J.; ANDRADE, J. C. S.; PALMA, H. - Substituição valvar por valva aórtica homóloga montada em suporte de glutaraldeído: estudo multicêntrico. Rev. Bras. Cir. Cardiovasc., 3(1): 1-8, 1988.

um trabalho de seguimento dessa bioprótese, provavelmente superior à que nós temos encontrado até o momento com as heterólogas. O grande valor deste trabalho, que nós vemos, além da participaçāo do Dr. Ênio, é o seu protocolo dirigido, principalmente, para o grande desafio, que são as substituiçōes valvares em crianças, por prótese biológica. Espera-se que haja confirmaçōes desses dados iniciais, num follow-up mais longo, comparando nossos resultados de substituiçōes com válvula de porco em criança, num grupo grande, que já foi apresentado em sessões anteriores. Nós vimos que a incidência de calcificação, depois do 5 : ano, é que é, realmente, muito significativa e muito expressiva e que mantém uma curva pior da que foi mostrada pelo autor da apresentação. A nossa dúvida, por se tratar de válvula humana, é se nós vamos ter possibilidade, em nosso meio, de suprir as necessidades de outros grupos. Outra questão, que nós deixamos como pergunta, é se, no protocolo, há uma rigidez em relação ao tempo após o óbito para um aproveitamento dessa válvula.

\section{DR. NILZO RIBEIRO}

\section{Salvador, $B A$}

O tema substituiçāo valvar é, sempre, motivo de discussão e a maior prova disso é o grande número de trabalhos deste Congresso sobre o tema. O que tem mudado, nas próteses biológicas? Parece-nos que a mudança é nos métodos de preservação tecidual. Pois nem os cirurgiōes mudaram, nem os tecidos e, aqui, reside uma premissa imutável - o tecido biológico sempre será perecível. E todos nós sabemos que os problemas começam após os 3 a 4 anos. No paciente jovem, a durabilidade tecidual tem-se mostrado menor, de tal modo que entendemos ser curto o espaço de tempo de 3 anos, para avaliação. Entendemos que todos os esforços devem ser tentados, na preservação valvar. Em nosso Serviço, dos 144 pacientes abaixo de 16 anos submetidos a cirurgia valvar, conseguimos preservar a valva mitral em $44 \%$ dos casos, sendo que $16 \%$ dos pacientes tinham idade inferior a 8 anos. A evolução pós-operatória, em um prazo médio de 7 anos, mostra que $57 \%$ dos pacientes estão inteiramente assintomáticos. Finalmente, perguntaria ao Dr. Énio qual o percentual de pacientes em que a preservação valvar foi obtida.

\section{PROF. ADIB JATENE \\ São Paulo, SP}

Eu queria cumprimentar o Dr. Ênio e os seus companheiros, pelo magnífico trabalho. Se a valva tratada com glutaraldeído, vamos dizer assim, grosseiramente, se transforma em um plástico, qual seria a diferença da válvula porcina para a valva humana, ambas tratadas com glutaraldeído? No resumo deste trabalho, são relatados 140 casos e 1 óbito $(0,7 \%)$, mas, na apresentação, estão 118 , com 3 óbitos. Tenho a certeza de que o
Dr. Ênio irá esclarecer esta diferença. As duas curvas atuariais apresentadas são de periodos diferentes. Nesse período, houve alguma melhoria, na preservação, tanto para quem faz as próteses porcinas, como para quem faz as próteses humanas, e se não seria interessante fazer, com a mesma técnica de preservação e com a mesma montagem, um estudo comparativo, já que a porcina é aceita universalmente e, pelos seus resultados, a prótese homóloga parece muito boa.

\section{DR. PAULO PAULISTA \\ São Paulo, SP}

Na realidade, eu iria fazer o comentário para discutir o aspecto que o Dr. Adib já levantou. O Dr. Ênio, no inicio da apresentação, mostrou uma valva muito bem cuidada e muito bem montada e de impressionante aspecto; ele mesmo levantou a importante questāo de que o enxerto é uma válvula melhor, tem todas as suas vantagens e existem vários processos de conservação, no mundo todo, para que essa válvula obtenha os melhores resultados possíveis, no paciente humano, e, entre esses processos, os mais adequados são, justamente, o uso da válvula fresca, conservada em solução nutriente e com antibiótico, antifúngico, ou, eventualmente, as criopreservadas. A vantagem de uma bioprótese heteróloga tratada com glutaraldeído é que o glutaraldeído faz com que ela fique exclusivamente plastificada e que seja aceita pelo organismo humano. Quando o Dr. Ênio pega uma valva homóloga e trata pelo mesmo glutaraldeido, ele não estaria apagando as vantagens dessa bioprótese, transformando-a em uma valva plastificada e, portanto, com resultados, a longo prazo, semelhantes àquelas que sã̉o obtidas com biopróteses heterólogas? Então, essa é a minha pergunta ao Dr. Ênio. Ele mostrou 2 curvas comparativas, feitas em tempos diferentes, por pessoas diferentes, como o Dr. Adib relatou, e ele mesmo disse que o resultado ainda não é significativo na diferença e, além do que, 48 meses não impressionam ninguém, em evolução de bioprótese. Muito obrigado.

\section{DR. PAULO RODRIGUES Rio de Janeiro, RJ}

Gostaria de cumprimentar os autores, pela excelência da qualidade deste trabalho. Várias ponderaçōes aqui já foram feitas e vários comentários também. $\mathrm{O}$ Dr. Énio, por seu espírito científico e sua honestidade profissional, fez as suas restrições pertinentes. Como já foi dito aqui, após o $4^{\circ}$ ou $5^{\circ}$ ano, é que os problemas ocorrem. O Dr. Ênio apresentou $52 \%$ de pacientes com 48 meses de seguimento, com menos de 15 anos de idade. O resultado que o senhor apresentou, com a calcificação em $52 \%$ de pacientes, em 4 anos, com menos de 15 anos, é superior a tudo o que existe na literatura. Meus parabéns. 
BUFFOLO, E.; SALLES, C. A.; VANDERLEY NETO, J.; MENDONÇA, J. T.; CASAGRANDE, I. S. J.; ANDRADE, J. C. S.; PALMA, H. - Substituição valvar por valva aórtica homóloga montada em suporte de glutaraldeído: estudo multicêntrico. Rev. Bras. Cir. Cardiovasc., 3(1): 1-8, 1988.

DR. CAMILO ABDULMASSIH NETO São Paulo, SP

Quero cumprimentar o Dr. Ênio e seus colaboradores, pelo trabalho e fazer apenas uma pergunta: como poderia ser solucionado o problema dos anéis de grande tamanho, 35, 33, 31, sabendo-se que a válvula aórtica tem dimensão menor e, em segundo lugar, esclarecer sobre o tratamento das válvulas heteróloga e homóloga, quanto ao tempo. Não foi no tratamento apenas com glutaraldeído, ou qualidade do glutaraldeído, como tem sido propalado. A válvula melhorou, quanto ao desenho do anel, quanto ao material mais apropriado para os suportes e houve inclusão de substâncias tampão, que não deixam existir os locais vazios na camada esponjosa do colágeno, que leva à deposição de elementos sangüineos, gorduras, etc., levando à calcificação precoce. Eu acredito que a melhora dos resultados do Dr. Énio deva ser o melhor tratamento atual da prótese. Obrigado.

\section{DR. PAULO POMERANTZEFF}

São Paulo, SP

Gostaria de cumprimentar o Dr. Ênio e sua equipe, pelo brilhante trabalho e gostaria de fazer duas perguntas: primeiramente, em qualquer tecido biológico tratado com glutaraldeído, devemos fazer teste de retração? Se esses testes têm sido feitos e quais são os resultados. $\mathrm{O}$ outro problema é com relaçẩo às biopróteses heterólogas, como, por exemplo, as biopróteses porcinas, é de serem montadas por dentro do anel, e nāo por fora. Vários estudos existem in vitro e in vivo, demonstrando os maiores gradientes. Gostaria de saber se o Dr. Ênio estudou os gradientes in vitro $\theta$ in vivo dessa prótese. Obrigado.

\section{DR. BUFFOLO}

(Encerrando)

São muitas as perguntas e eu vou procurar responder suscintamente. Quanto aos comentários do Dr. Hugo, nós agradecemos. Ele é uma das testemunhas do nosso trabalho, nesse campo, e eu gostaria de dizer a ele que um dos dados que nos impulsionou a desenvolver este trabalho foi a constatação que alguns daqueles 40 pacientes de minha tese de doutoramento, que foram operados de 1969 a 1971 se mantêm bem, inclusive duas crianças, uma com 12 anos e outra com 17 anos de evolução. Quando eu revi as crianças, mocinhas, uma delas veio trazer o convite de casamento, uma vez que, na época, o preparo era muito primitivo, as valvas eram conservadas em álcool, o tipo de suporte, diferente do atual, montada ao lado do paciente. Esses resultados fizeram com que a gente desse uma atenção maior e pensamos oferecer, para as homólogas, a tecnologia que utilizamos, hoje, para as heterólogas. Quanto ao tempo de obtenção dessas valvas, nos Insti- tutos Médico-Legais, elas são obtidas antes de 12 horas. O protocolo inicial era de menos de 6 horas, mas, por dificuldades no Instituto Médico Legal, esse prazo foi dilatado para 12 horas e a liberação da valva é feita por critério histológico. Existe uma série de informações, na literatura, e esses dados são absolutamente confiáveis de que o que preserva a valva da calcificação é o tecido vivo, se se consegue mànter um tecido vivo implantado, consegue-se ter uma valva livre de calcificação. As evidências disto são trabalhos, de muitos anos, do Dr. Barrat-Boyes. Recentemente, o Dr. O'Brien, na Austrália, estudou uma valva obtida de reoperação, com estudo cromossômico 11 anos depois. Era um indivíduo do sexo masculino e foi implantada uma valva aórtica homóloga de uma moça e, 11 anos após, ele conseguiu cultura de células dessa valva e essa cultura mostrou uma reprodução cromossômica de tipo feminino. Todos os autores que conhecem o assunto acham a atenção para que a viabilidade da valva é fundamental. Um outro atestado disto é apresentado pelos transplantes. Em informaçōes de literatura, de necrópsia de pacientes com transplantes, encontra-se arteriosclerose coronária, mas, excepcionalmente, encontram-se alterações valvares, tanto que isto tem estimulado alguns autores a adotar conduta de retirar a valva do coração do receptor e implantar, em uma sala paralela, essa valva em um outro doente aórtico. Quanto ao Dr. Nilzo, eu agradeço os comentários, apesar deles não terem sido referentes ao material apresentado e é muito difícil eu analisar qual o percentual de pacientes que sofreram a conservação da valva mitral, por ser um estudo multicêntrico e os dados que chegaram a nós foram dados da substituição valvar consumada. É evidente que todos os cirurgiōes aqui presentes têm suas técnicas de conservar uma valva mitral e preferem essa, como primeira opção, mas não foi este o objetivo da apresentação. As perguntas do Dr. Adib vão me dar uma oportunidade muito boa, porque ele tocou uns pontos que eu considero fundamentais e que, eventualmente, não tive oportunidade de discutir. Vocês sabem que, no início da substituição valvar por tecidos biológicos, houve uma competição muito grande entre valvas homólogas, que começaram antes, com Barrat-Boyes, em 1961-1962. Posteriormente, o Dr. Binet começou a substituição valvar com válvulas de porco, em 1965, e os resultados, com os mesmos processos de conservação da época, praticamente sepultaram as válvulas heterólogas, em 2 anos. Quer dizer, os trabalhos do Dr. Binet, na França, com válvulas heterólogas de porco, em 2 anos, estavam condenadas, ao passo que as homólogas conseguiram sobreviver a esse tipo de experimentação. Existem séries de dados teóricos, permitindo supor que a valva homóloga tem um melhor comportamento, a longo prazo. Existe uma publicação do American Journal of Cardiology, uma série de 3 artigos consecutivos de alguns anos passados, demonstrando que as válvulas heterólogas, apesar de plastificadas e vulcanizadas pelo glutaraldeído, conservam antigenicidade. Existe uma antigenicidade retardada, mas nitidamente evidente, quando essas válvulas são implantadas em subcutâneo de 
BUfFOlO, E.; SALLES, C. A.; VANDERLEy NETO, J.; MENDONÇA, J. T.; CASAGRANDE, I. S. J.; ANDRADE, J. C. S.; PALMA, H. - Substituição valvar por valva aórtica homóloga montada em suporte de glutaraldeído: estudo multicêntrico. Rev. Bras. Cir. Cardiovasc., 3(1): 1-8, 1988.

pacientes. Esses estudos precisaram ser suspensos, porque se acreditava que o implante simultâneo de parede aórtica no subcutâneo do paciente pudesse acelerar o processo de rejeição de válvula tratada pelo glutaraldeído. Então, existe uma expectativa de aceitação maior do mecanismo imunológico do indivíduo para as homólogas em relaçāo às heterólogas. Quanto à pergunta do Dr. Adib sobre os 140 pacientes, esse foi um resumo inicial que nós enviamos, contando com os dados do Dr. Regis, que era o $5^{\circ}$ grupo protocolado. Os dados do Dr. Regis foram exclusivamente com substituição de valva mitral, sem mortalidade hospitalar, mas, por nāo dispor de informaçōes tardias, achei que nāo devesse incluí-las. Eu aceito a crítica de que as curvas atuariais são de períodos diferentes e prejudicam a interpretação dos dados, e tenho a impressão de que não deixei claro essa crítica, no trabalho, mas aceito, perfeitamente. Não posso concluir cientificamente, mas existe uma impressão, da qualidade biológica da observação, de que essa valva, seguramente, é melhor, porque, apesar de o Dr. Paulo Paulista ter comentado que 4 anos nāo impressionam, 4 anos me impressionam, quando se trata de criança, porque, na nossa experiência com criança, não é preciso esperar 5 anos, para que as complicaçōes ocorram. Ainda respondendo ao Dr. Paulo, sem dúvida nenhuma, as válvulas frescas e as criopreservadas sāo as válvulas de melhor resultado e você poderia perguntar porque nós não partimos para isso, porque nós não fizemos válvulas frescas e válvulas criopreservadas, uma vez que a tecnologia nacional permite isto. Por 2 motivos: primeiro, porque tornaria isto praticamente um serviço artesanal e não ao alcance disponivel da prática médica diária; segundo, porque, com as válvulas criopreservadas e as válvulas frescas, você perde a oportunidade da montagem em suporte, o que inviabiliza uma substi- tuiçã valvar mitral e inviabiliza o problema de substituir um grande número de pacientes, motivo de tentar uma opção que permitisse um fornecimento industrial. Ao Dr. Paulo Rodrigues, eu gostaria de agradecer os comentários. O Paulo Rodrigues é, tradicionalmente, gentil com as nossas apresentações e, por isso mesmo, é que, no meu conceito, ele é suspeito. Quanto ao Dr. Camilo, o preparo de grandes tamanhos tem sido obviado com a variação do tamanho do colarinho de Teflon. Os maiores tamanhos das valvas aórticas homólogas alcançam montagens de 29 a 31 milímetros de diâmetro externo. Para grandes diâmetros de anel mitral, existem colarinhos 33, o diâmetro interno é o mesmo; o que varia é o tamanho do colarinho externo, como ocorre em outras valvas também. Até as válvulas de porco têm esse tipo de tratamento. Quanto ao preparo das valvas, eu não me sinto em condições de responder, por, realmente, não conhecer os pormenores. Quem tem preparado essas valvas é o Laboratório Labcor (à cópia e semelhança do preparo das válvulas heterólogas). Eu vou pedir desculpa ao Camilo, por não poder responder à pergunta e, praticamente, respondo, também, à pergunta do Dr. Pablo, sobre se essas valvas são testadas quanto à retração. Isso é um procedimento rotineiro, de quem fabrica válvula em escala industrial e eu acredito que isso também esteja sendo feito. Finalmente, quanto aos gradientes, não são motivo de preocupaçāo. Na nossa primeira revisão, em nossa tese de doutorado, com o mesmo tipo de procedimento, não analisamos todos os pacientes com cateterismo, tanto em posição mitral, quanto em posição aórtica. Os gradientes não impressionaram, tanto em repouso, quanto em exercício, e não tem motivo nenhum para essa valva ter um comportamento diferente das válvulas heterólogas. Muito obrigado pelos comentários. 